\title{
LA PROSTITUCIÓN Y LA ALCAHUETERÍA EN LA BARCELONA BAJOMEDIEVAL (SIGLOS XIV-XV)
}

\author{
Roger Benito Julià ${ }^{l}$
}

\section{RESUMEN}

Estudio de la organización de la prostitución en la Barcelona entre los siglos XIV-XV, en especial sobre las regulaciones del gobierno municipal sobre los burdeles, las formas de vida de las prostitutas y los alcahuetes y su expulsión. Contactos de la prostitución con diversas familias importantes barcelonesas: Gualbes, Terré, Carbó y sus estrategias matrimoniales. Relaciones de la prostitución con los monasterios barceloneses de Santa Clara, de las Arrepentidas y de Santa María Egipciaca.

Palabras clave: Barcelona, prostitución, siglos XIV-XV, familia Gualbes, alcahuetes, monasterios, mancebías.

\begin{abstract}
A study of the organization of the prostitution in Barcelona among the XIV-XV centuries, especially on the municipal government's regulations on the brothels, the forms of the prostitutes life and the pimps and their expulsion. Contacts of the prostitution with diverse important families from Barcelona: Gualbes, Terré, Carbó and their matrimonial strategies. Relate of the prostitution with differents monasteries from Barcelona: Santa Clara's, Penitents and Saint Mary Egyptian.
\end{abstract}

Key words: Barcelona, prostitution, XIV-XVth centuries, Gualbes family, pimps, monasteries, brothels.

\section{INTRODUCCIÓN}

Muchas veces para hablar de las mujeres en la Edad Media, hay que hablar de los hombres. Hablar de las mujeres en época medieval es difícil, pero hablar de las prostitutas medievales es

$1 \quad$ Universidad de Barcelona. Email: zadarbj@gmail.com. 
casi un reto. No tenemos fuentes directas que hablen de las prostitutas. Tenemos leyes, bandos, contratos... pero siempre escritos desde el poder y dando una visión masculina de la sociedad. La prostituta no deja testimonios. La conocemos a través de fuentes secundarias que hablan de ella.

En el presente trabajo abordaremos la vida de las prostitutas, los alcahuetes y alcahuetas que vivían en la ciudad de Barcelona entre los siglos XIV y XV. Con este fin, utilizaremos sobretodo fuentes documentales. ${ }^{2}$

La prostitución es una actividad permitida en toda la Europa Medieval. Nos preguntamos: ¿cómo una sociedad tan cristianizada permite la prostitución? Se considera la prostitución como un mal menor y tiene una función específica: evitar males peores. Estos males son: la sodomía, el adulterio, las violaciones, la masturbación... San Agustín de Hipona escribe: "Apartad las prostitutas de los asuntos humanos y profanaréis todo con lujuria." Posteriormente San Tomás de Aquino apoyó esta idea en la Summa de Teología. ${ }^{4}$ El fraile franciscano Francesc Eiximenis en su obra Lo Crestià, recoge el testimonio de San Agustín y añade que las mujeres públicas no deben mezclarse con las honradas. ${ }^{5}$ Esta idea extendida por toda la Europa Medieval choca con nuestra mentalidad actual pero es vital para entender la prostitución en la Edad Media.

\section{CAUSAS}

La prostituta tiene una condición impuesta. No vende su cuerpo por placer sino por necesidad. Las causas son múltiples. La raíz es la falta de medios económicos. La falta de dinero para la mujer en la Edad Media era muy común, dado que, muchas no trabajaban y las que lo hacían estaban mal remuneradas. Hemos documentado (1414) en Barcelona esclavas que, para pagar su manumisión, habían de prostituirse. ${ }^{6} \mathrm{Si}$ esta situación se descubría, el castigo era para la esclava, debido a que, la mayoría de cautivas pertenecían a familias nobiliarias y patricias de la ciudad. El desarraigo geográfico se une a esta falta de recursos económicos. Muchas de las mujeres públicas de la ciudad eran forasteras. Hemos documentado prostitutas de Zaragoza, Asturias, Toledo, Burgos, León, Perpiñán, Valencia, Galicia, entre otros lugares. Una mujer llegada a una ciudad que no conocía, podía caer en manos de un alcahuete o una alcahueta. La falta de dote para casarse podía obligar a una doncella a prostituirse. La mujer que sufriera una violación también podía ser una causa para caer en las redes de prostitución. La dificultad de una mujer marcada para casarse podía obligarla a prostituirse.

\section{EL CONTROL INSTITUCIONAL}

El gobierno municipal barcelonés, llamado Consell de Cent, estableció, a lo largo del siglo XIV, una serie de reglamentaciones. Éstas son no para combatir la prostitución sino

\footnotetext{
2 Hemos utilizado fuentes de tres archivos. Abreviaturas utilizadas: ACA: Archivo de la Corona de Aragón; AHCB: Arxiu Històric de la Ciutat de Barcelona; ACVD: Arxiu del Castell de Vilassar de Dalt.

3 "Aufer meretrices de rebus humanis, turbarevis omnia libidinibus". San Agustín de Hipona: De Ordine, 11.4.12.

4 “Así, pues, en el gobierno humano, quienes gobiernan toleran también razonablemente algunos males para no impedir otros bienes, o incluso para evitar peores males”. San Tomás de Aquino: Summa de Teología. Parte II-II. Q. 10-A.11.

5 EIXIMENIS, Francesc: Lo Crestià. Barcelona, Edicions 62, 1983, capítulo DLXXIV, p. 155.

6 AHCB, Consell de Cent, Llibre del Consell XXIX, fol. 1r.
} 
para que la convivencia entre mujeres públicas y los demás ciudadanos sea lo más pacífica posible.

A principios del siglo XIV, el Consell, prohíbe que las mujeres públicas tengan las puertas abiertas de sus casas, ni enciendan velas, después del toque de campanas llamado seny del lladre, cuando se cerraban las puertas de la ciudad. ${ }^{7}$ Esta prohibición se da en la calle de Viladalls, vía en que posteriormente se establecerá uno de los tres burdeles barceloneses. En el año 1340 se emite una proclama para que las prostitutas vistan sin manto mientras trabajan. Si las mujeres desobedecían esta disposición se las obligaba a pagar 20 sueldos barceloneses o a estar un día de prisión. ${ }^{8}$ Esta medida es para diferenciarlas de las mujeres honradas. Estos bandos se irán repitiendo a lo largo de los siglos XIV y XV. San Vicente Ferrer aconseja que las mujeres honradas vayan cubiertas si no se quiere que se las confunda con prostitutas. ${ }^{9}$

El mismo Consell obligaba a las mujeres públicas a enclaustrarse durante la Semana Santa, en el monasterio de Santa Clara de Barcelona. El motivo según el documento del 22 de marzo de 1373 era que los hombres se abstuvieran de ir con ellas y así poder seguir los preceptos de la abstinencia carnal en Semana Santa. ${ }^{10}$ Se establece que las mujeres estarán recluidas desde el Miércoles Santo hasta la tarde del lunes de Pascua. Durante este tiempo podrán ocupar tres habitaciones del monasterio. Estaban con ellas cuatro hombres de confianza del Consell. Estos mismos habían echo la proclama por toda la ciudad el lunes y el martes anterior al dicho periodo de reclusión. Contaban con la ayuda de un cap de guaita y dos saigs (sayones), encargados de la seguridad. El mismo gobierno municipal las proveía a las mujeres de todo lo necesario para su reclusión: leña, comida y lechos para su descanso. El Consell les proporciona consuelo espiritual: las obliga a asistir a misa todos los días de enclaustramiento y también se proporcionan confesores por si las mujeres quieren arrepentirse de su vida pecadora. Se prohíbe que ningún alcahuete se acerque al monasterio mientras dure la reclusión y en caso contrario sería azotado y paseado en burro por la ciudad. Esta misma pena era la reservada para las mujeres que escapasen del monasterio durante el período establecido. Algunos gastos eran sufragados por el gobierno municipal y otros con donaciones. En el año 1373 se destinaron cien sueldos barceloneses, recaptados por viudas y mujeres honestas en la ciudad. ${ }^{11}$ Posteriormente a partir del siglo $\mathrm{XV}$, se las recluía en el Monasterio de las Egipciacas, del cual hablaremos más adelante. En este momento sólo se las enclaustra durante tres días (del Miércoles Santo al Viernes Santo) y se encarga la vigilancia a una mujer, llamada maioral o abadesa. Ésta se encarga de toda la intendencia. Esta reclusión durante la Semana Santa no es exclusiva de la ciudad de Barcelona. La hemos documentado en la ciudad de Valencia ${ }^{12}$ y también en las ciudades del sur de Francia estudiadas por Jacques Rossiaud. ${ }^{13}$

\footnotetext{
7 AHCB, Consell de Cent, Llibre del Consell VIII, fol. 24v.

8 AHCB, Consell de Cent, Llibre del Consell XV, fol. 35r.

9 Sant Vicent Ferrer: Sermons (Vol. III), Barcelona, Editorial Barcino, 1932, p. 256-257.

10 AHCB, Consellers, Miscel·lània $1 \mathrm{C}-\mathrm{V}-13 / 1$, fol. 2

11 AHCB, Consellers, Miscel·lània 1C-V-13/1, fol. 2

12 VILLANUEVA, Joaquín Lorenzo: Viage literario á las iglesias de España. Vol I: Játiva y Valencia. Madrid, Imprenta Real, 1803, p. 160. El documento es de 1385.

13 ROSSIAUD, Jacques: La prostitución en el medievo. Barcelona, Ariel, 1986, p. 15. En algunas de estas ciudades se cierra el burdel durante Navidad.
} 
Después del ataque de la judería de la ciudad el año 1391, muchas prostitutas se instalaron en las casas que dejaron libres los judíos de Barcelona. En 1396 el rey Juan I promulgó una disposición prohibiendo que los hombres moren con las prostitutas de la judería. El argumento usado es muy simple: evitar la multiplicación de los vicios de la ciudad y los males sanitarios. Los hombres que estén con las prostitutas serán sancionados con 200 florines de oro. Era mejor que las mujeres vivieran lejos del centro neurálgico de la ciudad y que moraran cerca de las murallas y los portales.

Anteriormente se obligó a las prostitutas judías de la ciudad a marcharse en 1374. En el mismo bando se prohíbe que ningún judío ose tener una mujer pública trabajando en su casa. El sexo entre miembros de diferentes religiones está penado. El código legal llamado Costums de Tortosa del siglo XII, lo deja muy claro: "Si jueus o sarrains seran trobats jaen ab crestiana lo jueu o el sarrai deuen esser tiraçats e rocegats, e la crestiana deu esser cremada: en manera que muyren". ${ }^{14}$

\section{LOS BURDELES BARCELONESES}

A lo largo de los siglos XIV-XV documentamos en Barcelona tres burdeles: Viladalls, La Volta d'en Torre y El Canyet. Los tres burdeles son edificios públicos que el gobierno municipal alquila a quien los quiera explotar. El burdel, al igual que en el resto de la Europa Medieval, tenía el monopolio de la prostitución en las ciudades. La mayoría de las mancebías medievales se encuentran cerca de las murallas de la ciudad. Es el caso de los tres burdeles barcelonenses. Los tres están adosados a la muralla, el de Viladalls y La Volta d'en Torre están cerca de la actual Rambla, el primero próximo del Portal de la Boquería y el segundo cerca del Portal de la Portaferrissa; el burdel de El Canyet lo situamos en el otro lado de la ciudad, cerca del Portal de San Daniel.

Según la documentación el más antiguo de estos burdeles era el de Viladalls. Ya hemos apuntado que en la calle de Viladalls había prostitución doméstica antes de que se creara el burdel. Esta mancebía estaba delimitada entre las calles del Vidre, la calle de la Boquería, la calle de Rauric, la calle Dels Ollers. Algunas de estas calles aún están en el nomenclátor barcelonés. Sabemos gracias a un contrato de arrendamiento ${ }^{15}$ del 19 de junio de 1397 , como funcionaba internamente el burdel y como era externamente. El arrendador Joan Mugull, ciudadano de Barcelona, arrienda a Pere Coll y a su esposa Margarida el control del burdel a partir del primero de agosto del dicho año. Pere y Margarida se convierten así en hostalers de bordell (hosteleros de burdel), que son los que controlan el funcionamiento del lupanar. El burdel consta de dos partes: el hostal con las habitaciones y las casas del huerto. En la primera parte se servía comida y bebida para las mujeres públicas y a los clientes. Las habitaciones servían para que pudieran prestar sus servicios. Las casas situadas en el huerto eran para que las mujeres descansaran. El burdel tal como vemos no era un sólo edificio sino que era una infraestructura de edificios con funciones diferenciadas.

14 Si judíos o musulmanes serán encontrados acostados con cristiana, el judío o el musulmán serán tirados y arrastrados, y la cristiana ha de ser quemada: de manera que mueran. Costums de Tortosa, IX.2.7. Citado por BOSWELL, John: The Royal Treasure: Muslim Communities Under the Crown of Aragon in the Fourteenth Century, New Haven, Yale University Press, 1977, p. 344.

15 AHCB, Arxiu Notarial, IX.3 (Carpeta Bordells). Sin foliar. 
Los hosteleros, según el contrato, tenían que cobrar cada semana de las mujeres el dinero o objetos por el uso del hostal o las casas del huerto. Estas rendas serían entregadas cada sábado a Joan Mugull. Los hostalers no pueden fiar a ninguna mujer pública, ya que existe el riesgo que esta escape sin pagar. En el contrato se recomienda a Pere y Margarida que respeten las ordenanzas del Consell de Cent, ya que las posibles sanciones irán a su cargo. También son responsables de los objetos del interior del burdel y del mantenimiento de los edificios que forman la mancebía. Mugull proporciona al burdel dos esclavas para hacer las camas, barrer y atender las posibles necesidades de las mujeres que trabajaban en el prostíbulo. Los dos hosteleros tienen derecho a una habitación privada, siempre que mantengan al menos cuatro habitaciones para las prostitutas. Pueden si quieren dar comida y bebida a las mujeres sin dar nada a Joan Mugull.

En el siglo XV los arrendadores de los burdeles de Viladalls y de la Volta d'en Torre formaban parte de las familias más importantes de la ciudad. A lo largo del siglo XIV Ferrer de Gualbes, caballero de la ciudad de Barcelona, compró varias propiedades en el lugar de Vialdalls en $1434 .{ }^{16}$ Ferrer controlaba el burdel homónimo de Viladalls y por eso le interesaba obtener esas propiedades, para aumentar el negocio. Ferrer de Gualbes aparece en un privilegio (fechado en julio de 1446) otorgado por el rey Alfonso el Magnánimo, a los señores útiles de las dos mancebías de la ciudad. ${ }^{17}$ En el documento nos indican que los señores útiles de los burdeles son Ferrer de Gualbes, Joan de Camós, Narcís Mugull y Elionor Terrera. El rey Alfonso ratifica en el privilegio que ninguna mujer pública pueda trabajar fuera del los dos burdeles oficiales. La familia Gualbes era una de las más importantes de la ciudad de Barcelona e incluso tenían cargos dentro del Consell de Cent. Los Camós eran un linaje de comerciantes muy activos en la ciudad. La familia Mugull, tal como hemos visto, había estado ligada al mundo de la prostitución. Elionor Terrera era viuda de Joan Terré (por eso se la llama "Terrera"), formaba parte de una familia de comerciantes. Ferrer y Elionor eran cuñados. Ferrer estaba casado con una hermanastra de Elionor, llamada Beatriu Carbó..$^{18}$ Elionor controlaba directamente el burdel de la Volta d'en Torre. Estos mismos señores de los burdeles tuvieron un contencioso con el Consell de Cent; el problema vino dado por una puerta del burdel de La Volta d'en Torre que daba directamente a la Rambla de Barcelona. La Rambla fue canalizada en $1364{ }^{19}$ y embellecida como paseo desde entonces. El gobierno municipal se quejaba de la mala imagen que daba el burdel en el paseo por eso había cerrado la puerta que daba al paseo, en el año $1440^{20}$. Los señores del burdel interpusieron varias quejas al Consell entre los años 1440 y 1453. Finalmente el año siguiente se solucionó el problema construyendo un recodo para que el interior del lupanar no fuera visible desde la Rambla ${ }^{21}$. Tanto Ferrer como Elionor dejan sus bienes a Ferrer de Gualbes, hijo y sobrino respectivamente llamado como su padre. El

16 ACVD, 6-7-12 (B-10).

17 AHCB, Consell de Cent, Diversorum 1B-XV-4, fol. 257r.; ACVD, 41-1-04 (B-8); En el documento aparecen como utilum dominorum luppanarium eiusdem civitatis vulgariter dictorum Viladalls e de la Volta den Torra.

18 Véase árbol genealógico del apéndice.

19 CARRERAS CANDI, Francesc; GUNYALONS BOU, Bartomeu: Rúbriques de Bruniquer (Vol. IV). Barcelona, Ajuntament de Barcelona, 1915, p. 52.

20 AHCB, Consell de Cent, Registre de Deliberacions, 1B-II-2, fol. 118r.

21 AHCB, Consell de Cent, Registre de Deliberacions, 1B-II-8, fol. 199r. 
testamento de Elionor fue ordenado en 1450 y el de Ferrer de Gualbes en 1452. ${ }^{22}$ Ferrer de Gualbes (hijo) fue concentrando propiedades cerca del burdel de Viladalls. En 1492 compró a Joan de Gualbes dos casas y un taller que este poseía por 9 libras barcelonesas cerca del burdel de Viladalls.

El burdel de El Canyet, llamado también Hostal d'en Sala, lo documentamos por primera vez en el año 1443. En este documento se investiga la paliza y posterior robo a la mujer pública Joana, apodada "la griega". Los burdeles eran sitios ruidosos y las riñas y escaramuzas eran frecuentes. El interrogatorio empieza con Diego de Salinas, marinero afincado en la ciudad, procedente de la villa de Cardona. El marinero afirma que trabaja de alcahuete y que con anterioridad ha tenido mujeres trabajando por él dentro del burdel. Diego afirma que la noche de la paliza Joana había dormido con Antonet, pescador de la ciudad, y que le habían dicho que éste le propinó la paliza y le robó unas ropas y una lanza elaborada en Jerez. Los otros testimonios de la pesquisa afirman que han oído que el pescador es quien dio los azotes a Joana. ${ }^{23}$ Posteriormente el burdel de El Canyet aparece en las órdenes de expulsiones de los alcahuetes y alcahuetas de la ciudad ${ }^{24}$, pero a partir de 1457 no tenemos más noticias de la mancebía. Hemos localizado otras mujeres maltratadas por su condición de prostituta. En 1428 Caterina llamada "la monja”, mujer pública de la ciudad de Valencia, abrió diligencias contra Joan de Llorenç, empleado de la casa del rey. Caterina era la favorita de Joan, pero la mujer pidió ayuda a las autoridades por las reiteradas palizas que le propinaba el dicho Joan..$^{25}$

\section{FUERA DEL BURDEL}

Paralelamente a la prostitución dentro del burdel existía una prostitución que escapaba del control del gobierno municipal. Este comercio sexual era un poco más difuso. Eran mujeres que trabajaban por su cuenta en su casa, en la calle o en los hostales, no considerados propiamente como burdeles. El municipio barcelonés expulsó el 1441 a Violant (procedente de Valencia) por cantonera (esquinera); un año después tres prostitutas que trabajaban en la muralla también fueron echadas de la ciudad. ${ }^{26}$ Encontramos diversas prohibiciones, ordenadas por el Consell de Cent y a veces por el mismo rey con el fin de que las prostitutas estuvieran fuera de ciertas calles. A lo largo de los siglos XIV y XV encontramos prostitutas en las calles de Sant Pol, esquina con la calle Robador (1339), la calle D'en Roca (1340), la calle de Na Quintar (1356), la calle del Vidre (1367 y 1390), la calle del Veguer (1414), la calle Banys Nous, el Portal de la Boquería y el Portal de Santa Eulàlia (1443), la calle Juglar (1441), el Portal de Frares Menors (1453), entre otros muchos. ${ }^{27}$ A estas mujeres se les hacía pagar una multa en dinero o bien estarse unos días en prisión. Los vecinos ejercían de delatores y acusadores cuando sospechaban de alguna mujer que vivía sola. El gobierno municipal investigó

\footnotetext{
22 ACVD, 1-75-42 (E-5); ACVD, 1-70-30 (A-1).

23 ACA, Cancelleria, Processos en quart, 1443.

24 AHCB, Consell de Cent, Registre d'Ordinacions Especials, 1B-V-12.

25 ACA, Processos en quart, 1428.

26 AHCB, Consell de Cent, Registre d'Ordinacions Especials, 1B-V-12, fol. 38r. y fol. 40r.

27 Ver el mapa en el apéndice.
} 
a Eulàlia de la calle del Bot, en $1405 .^{28}$ En la indagación se hacen tres preguntas básicas: si la mujer es prostituta, si es alcahueta y si es malhablada. Uno de los interrogados, Domingo Ram, dice que está dando mal eximpli (mal ejemplo) en todo el vecindario. Eulàlia, ya había sido expulsada de la calle de Bertrallans por ejercer la prostitución en su casa. Domingo afirma que Eulàlia sale de noche con la cabeza cubierta y va donde quiere. Además vive sola y recibe hombres en la casa. Otro testimonio, Maria, esposa de Joan Albagés, afirma que Eulàlia, estuvo casada anteriormente pero que estando casada se había ido con otro hombre. El documento no deja claro si Eulàlia se prostituye pero deja claro que los vecinos por medio de delaciones quieren controlar la moral de la vecindad.

Otra mujer investigada fue Clara, que moraba cerca del convento de los Frailes Menores. El documento ${ }^{29}$ es de 1415 y usa el mismo cuestionario que en el caso de Eulàlia. Según las palabras de Guillem Ramon Sala, maestro de casas, en la casa de Clara entran hombres de diversas condiciones, los cuales comen, beben y yacen con ella. Angelina, esposa de Guillem, afirma rotundamente que es àvol fembra, (mala mujer) eufemismo para referirse a las prostitutas. Clara según otros vecinos preguntados es muy maldiciente y amenaza constantemente a los vecinos.

Las autoridades persiguen a la prostituta que trabaja fuera del burdel. Tanto estas investigaciones de estas dos mujeres, como las prohibiciones de estar en ciertas calles, son para proteger el negocio del municipio (el burdel), como los clientes de ese negocio (los arrendadores).

\section{LA ALCAHUETERÍA}

El alcahuete y la alcahueta son figuras claves en la prostitución que se realiza fuera del burdel. Tal y como afirma un bando barcelonés del 19 de abril de 1302, se entiende por alcahuete el que tiene mujeres públicas y vive de los pecados de ellas. ${ }^{30} \mathrm{Al}$ alcahuete normalmente se le expulsa de la ciudad. En el documento citado se les da un día para que abandonen la ciudad, si no serían azotados mientras eran paseados por la ciudad montados a lomos de un burro. Se irán repitiendo ordenanzas similares a lo largo del siglo XIV. En 1326 se prohíbe que los rufianes alquilen a las mujeres ropas o camastros. ${ }^{31}$ Este asunto no se solucionó, por lo que el rey Pedro III promulgó una pragmática real en las cortes de 1375, celebradas en la ciudad de Lleida, contra los alcahuetes que prestaban ropa y lechos a las mujeres públicas. ${ }^{32} \mathrm{El}$ municipio expulsará a los rufianes que serán encontrados cerca del Portal Dels Tallers. A éstos les será quitada la ropa de sus casas y tendrán que abandonar la ciudad en los próximos diez días (1340). ${ }^{33}$

No será hasta 1390 que las cosas cambiarán. El rey Juan I promulga un privilegio ${ }^{34}$ a favor de la ciudad de Barcelona endureciendo las penas contra los alcahuetes. El privilegio

28 AHCB, Consellers, Miscel-lània 1C-V-13/1, fol. 3r.

29 AHCB, Consellers, Miscel·lània 1C-V-13/1, fol. 6r.

30 AHCB, Consell de Cent, Llibre del Consell de Cent I, fol 26v.

31 AHCB, Consell de Cent, Llibre del Consell de Cent IX, fol. 17r.

32 Cortes de los antiguos reinos de Aragón y de Valencia y principado de Cataluña, publicados por la Real Academia de la Historia. Tomo III: cortes de Cataluña III (1368-1375), Madrid, 1900, p. 305.

33 AHCB, Consell de Cent, Llibre del Consell XV, fol. 32v.

34 ACA, Registres de Cancelleria, 1844, fol. 184r. 
se pone a la práctica a partir de 1398. A partir de ahora los pregoneros de la ciudad irán por las calles pregonando los nombres de los inculpados de alcahuetería. ${ }^{35}$ Estos pregones se solían dar dos veces al año. Los alcahuetes deben marcharse de la ciudad diez días después del anuncio, o, como era de costumbre, serían azotados mientras eran paseados a lomos de un burro. Según el privilegio tenían derecho a presentar alegaciones y súplicas para que se les permitiera vivir en la ciudad, prometiendo ser respetuosos con la ley. Estas penas de exilio iban desde un año hasta los cincuenta, a los que fue condenada la meretriz Àgata la geperuda (la jorobada), en 1459. La gran mayoría eran condenas entre diez y veinte años. Algunos obtenían la venia de la ciudad y la sentencia no se ejecutaba. Si un alcahuete expulsado reincidía y se le encontraba dentro de los muros de la ciudad después de ser expulsado se le mandaba diez años a galeras en la isla de Cerdeña. Finalmente si volvía a reanudar sus actividades, después de su exilio en galeras, se le colgaba de las horcas de la ciudad, situadas normalmente en los portales de las murallas y en la Rambla.

Cuando hablamos de alcahuetes y alcahuetas todos tenemos en mente las alcahuetas literarias, como la Celestina de Fernando de Rojas, o la Trotaconventos del Libro de Buen Amor del Arcipreste de Hita. La literatura presenta a las alcahuetas como embaucadoras, falsas, hipócritas que engañan a la gente. Se las presenta como mujeres viejas tal como describe el Arcipreste a Trotaconvetos:

“Era vieja bufona d'éstas que venden joyas: / Éstas echan el laço, éstas cavan las foyas; / Non ay tales maestras como estas viejas troyas, / Éstas dal la maçada: si as orejas, oyas." ${ }^{, 36}$

No hemos localizado, de momento, ningún protagonista masculino, en la literatura medieval, que sea alcahuete. La literatura medieval nos da un modelo femenino de rufián que no se ajusta con la documentación historia de la ciudad de Barcelona. Hemos localizado entre los años 1401 y 1460, 642 alcahuetes en los registros de expulsión. De estos sólo 79 eran mujeres (un 12,33\%) y el resto, 562 eran hombres (un 87,67\%).

Fernando de Rojas presenta La Celestina como una mujer con muchos oficios para poder entrar en contacto con mujeres para prostituirlas: "Ella tenía seis oficios, conviene [a] saber: labrandera, perfumera, maestra de hacer afeites y de hacer virgos, alcahueta y un poquito de hechicera" ${ }^{37}$ En los registros de expulsión a veces se indica otros oficios de los alcahuetes. De un total de 176 alcahuetes con oficios definidos, encontramos a barberos (33), sastres (13) pelaires (10), zapateros (9), herreros (8), escribientes (6), peleteros (6) entre otros. Muchos de los alcahuetes y alcahuetas de la ciudad explotaban las mujeres para redondear sus ingresos. ${ }^{38}$ De 163 expulsados se nos indica que provienen de fuera de la ciudad. De Valencia son 32 alcahuetes expulsados, pero también los hay de Castilla (19), Perpiñán (7), Aragón (6), Lleida (6), Mallorca (5), Gascuña (5). Encontramos alcahuetes de lugares muy lejanos como Cerdeña (5), Sicilia (2), Nápoles (1) o Portugal (1). A veces el

35 La mayoría de estos pregones se encuentran en: AHCB, Consell de Cent, Registre d'Ordinacions Especials, 1B-V-12. Los datos aquí expuestos son de este volumen.

36 RUIZ, Juan: Libro de Buen Amor, Barcelona, Crítica, 2001. Copla 699.

37 ROJAS, Fenando de: La Celestina. Madrid, Alianza Editorial, 1998, p. 70-71.

38 Véase cuadro del apéndice. 
registro de expulsiones nos da otros datos sobre los expulsados. Hallamos alcahuetes conversos, esclavos y esclavas, hombres que trabajan para el rey, para el veguer, ciudadanos honrados de Barcelona o incluso un hombre casado, Gallard de Montfalcó que liura la seva muller a homens per diners (entrega su esposa a hombres por dinero). ${ }^{39}$

El mayor logro para un alcahuete era colocar a sus mujeres para que trabajasen en el burdel sin pagar rendas a los hostalers de bordell. En el registro de expulsiones encontramos a varias mujeres que trabajan ilegalmente en el burdel. En el burdel de Viladalls entre 1436 y 1460 encontramos a 134 mujeres trabajando ilegalmente en dicho burdel. En La Volta d'en Torre hallamos a 66 mujeres, entre los años 1439 y 1454. Finalmente en el burdel de El Canyet localizamos muchas menos, sólo 14, entre los años 1444 y 1457.

\section{MONASTERIOS Y PROSTITUCIÓN}

Además del monasterio de Santa Clara, anteriormente citado, encontramos dos monasterios más relacionados con la prostitución en la ciudad de Barcelona. El monasterio de las Magdalenas (o Arrepentidas) y el de las Egipciacas. El primero fue empezado a edificar en 1365 gracias a las 500 libras donadas por el Consell de Cent. Formalmente fue fundado en el año 1372, ${ }^{40}$ con la bendición del obispo de Barcelona, Pere de Planella. El monasterio fue organizado bajo la regla se San Agustín. Estaba situado en la actual calle de Les Magdalenes. El monasterio recibía cada año la cantidad de mil libras procedentes del Consell de Cent. ${ }^{41}$ Este monasterio tenía la finalidad básica de acoger a antiguas prostitutas para que se arrepintieran de su antigua vida. Hemos documentado monasterios dedicados a Santa María Magdalena, con la misma finalidad, en la ciudad de Valencia y Palma de Mallorca. ${ }^{42}$ El segundo monasterio era el de las Egipciacas. Fue fundado en 1409, aunque hay fuentes que dicen que fue un año después. ${ }^{43}$ Un cartujo de Mallorca, Francesc de Valldemosa, fue quien compró unas casas al lado de la calle d'en Canyet, hoy llamada Egipciaques, para construir un centro asistencial bajo la advocación de Santa María Egipciaca. Este centro tenía la finalidad de recoger a las mujeres públicas que quisieran abandonar su vida. También se recogían huérfanas, a las que se les imponía una serie de normas de conducta, comida, dormir, oración, como si se tratara de un auténtico espacio conventual. A diferencia de las Arrepentidas las Egipciacas no seguían ninguna regla monástica determinada. Este monasterio se inscribía dentro del Hospital de la Santa Creu. Éste aglutinaba todos los hospitales de pobres de Barcelona desde 1401. Ya hemos apuntado que en la Semana Santa de 1437 se recluyeron en este monasterio a las prostitutas de la ciudad. El funcionamiento era muy parecido al enclaustramiento del monasterio de Santa Clara. Parece que este monasterio

39 AHCB, Consell de Cent, Registre d'Ordinacions Especials, 1B-V-12, fol. 69v-70v.

40 CARRERAS CANDI, Francesc; GUNYALONS BOU, Bartomeu: Rúbriques de Bruniquer (Vol. III), Barcelona, Ajuntament de Barcelona, 1914, p. 71 y 72.

41 AHCB, Consellers, Testaments de Consellers 1C-XVII-1 (Año 1371) fols 8v.-9r.

42 CÁRCEL ORTÍ, Ma Milagros: "Vida y urbanismo en la València del siglo XV", Miscel-lània de Textos Medievals 6. (1992); ROSSELLÓ VAQUER, Ramon: Les cases de penedides a la ciutat de Mallorca, Ciutat de Mallorca, Llibreria Jovellanos (Col·lecció Jovellanos nº 9), 1992.

43 CARRERAS CANDI, Francesc; GUNYALONS BOU, Bartomeu: Rúbriques de Bruniquer (Vol. III), Barcelona, Ajuntament de Barcelona, 1914, p. 298; HERMANO DE LA CARIDAD: Los hermanos del hospital de la Santa Cruz, Barcelona, Librería Casulleras, 1935, p. 19. El segundo afirma que se fundó en 1410. 
era una especie de centro reclutador para las mujeres que no seguían una vida honesta o dentro de la normalidad. En 1449 se recluyó a Caterina, esposa de Rafael de Olzinelles, ya que se había vuelto loca. ${ }^{44}$ Posteriormente en 1459 se encerró a una mujer que vivía con un sacerdote. ${ }^{45}$ No es casual que ambos monasterios estuvieran bajo estas advocaciones. Desde el siglo XII se habían incorporado en el calendario medieval estas dos santas. ${ }^{46}$ Tanto la Magdalena como María Egipciaca habían sido santas después de ser pecadoras. En Barcelona sabemos que tenían cierto culto. Existían capillas de Santa María Magdalena en la Catedral de Barcelona y en el hospital de Sant Joan de Jerusalem. ${ }^{47}$ En la procesión de Corpus del año 1424 se mostraron las reliquias de Santa Maria Magdalena y Santa María Egipciaca. También se representó, en la misma procesión, un entremés dedicado a Maria Magdalena a cargo de los frailes mercedarios. ${ }^{48}$

\section{PARA CONCLUIR}

En el presente artículo hemos intentado explicar como se organizaba la prostitución en la ciudad de Barcelona. Las primeras regulaciones son de principios del siglo XIV. Si bien se permitía la prostitución en la ciudad, sólo se permitía dentro de una de las tres mancebías oficiales. Estos burdeles, tal y como hemos visto, eran propiedad del gobierno municipal. El Consell de Cent las arrendaba para sacar beneficio, siempre dentro del marco de la idea de mal menor que ya hemos expuesto. Los arrendadores eran personajes de la burguesía barcelonesa y operaban con estos burdeles como cualquier otra propiedad. Es por eso que, como hemos descrito, se desarrolla una cierta política matrimonial para aglutinar el máximo número de burdeles bajo la misma familia: los Gualbes. Ir al burdel, no comportaba ningún dilema moral. Era un hecho normal y aceptado por la sociedad. El gobierno municipal protege a los que arriendan el burdel. Se multan o encarcelan a las prostitutas que trabajan por libre y se expulsan a los alcahuetes y alcahuetas de la ciudad. La verdadera lucha es contra estos últimos. El poder real interviene y otorga el privilegio de 1390 a la ciudad, para aumentar las penas a los rufianes y ahorcarlos en casos extremos. El modelo de la alcahueta literaria no es aplicable a la ciudad de Barcelona ya que documentamos más alcahuetes que alcahuetas. El Consell busca soluciones para las prostitutas retiradas y las encuentra: las enclaustra. Por eso crea el Convento de las Magdalenas y utiliza la Casa de las Egipcíacas.

Durante la Edad Moderna la idea de mal menor irá disolviéndose para pasar a la prohibición de la prostitución y el establecimiento de las cortesanas. En 1621 Felipe IV prohibiría la prostitución en Castilla y tres años después en el Reino de Aragón. ${ }^{49}$ A pesar de las prohibiciones, regulaciones y demás, de reyes, gobiernos y municipios, es una actividad que aún no se ha regulado y que sigue siendo alegal en nuestro país.

44 AHCB, Consellers, $1 \mathrm{C}-\mathrm{V}-13 / 2$, fol. $2 \mathrm{r}$.

45 AHCB, Consell de Cent, Registre de Deliberacions, 1B-II-12, fol. 142v.

46 Véase: DUBY, Georges: Damas del siglo XII. Eloísa, Leonor, Iseo y algunas otras, Madrid, Alianza Editorial, 1995, pàgs. 35-62; y también SÁNCHEZ ORTEGA, M Melena: Pecadoras en verano, arrepentidas de invierno, Madrid, Alianza Editorial, 1995.

47 ACVD, 1-65-08 (D-5); ACVD, 1-14-12 (C-7).

48 DURAN I SANPERE, Agustí; SANABRE, Josep: Llibre de les solemnitats de Barcelona, Barcelona, Institució Patxot, 1930, p. 12 y siguientes.

49 Novísima Recopliación de las leyes de España, Lib. XII, tít. XXVI, ley VII. 


\section{APÉNDICES}

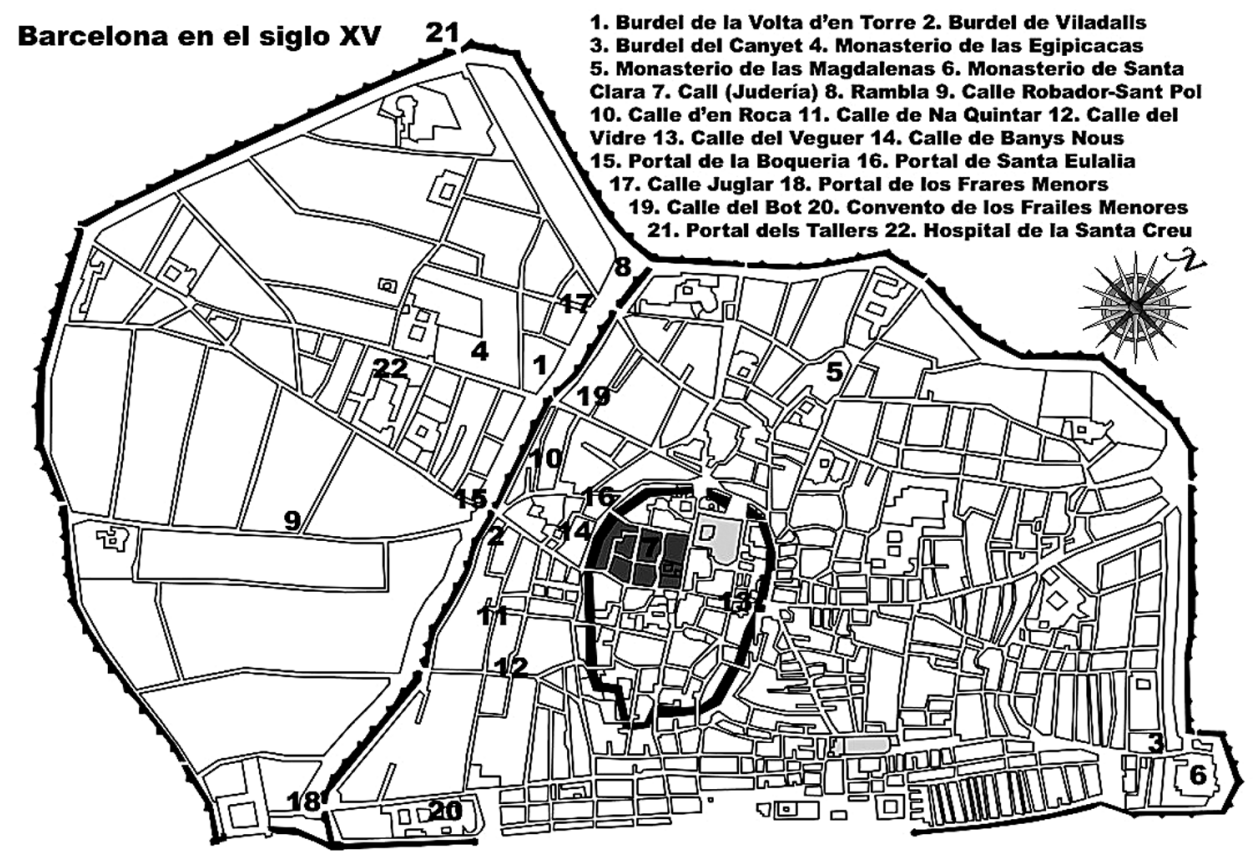

LOS SEÑORES DE LOS

BURDELES DE VILADALLSY

DE LA VOLTA D'EN TORRE

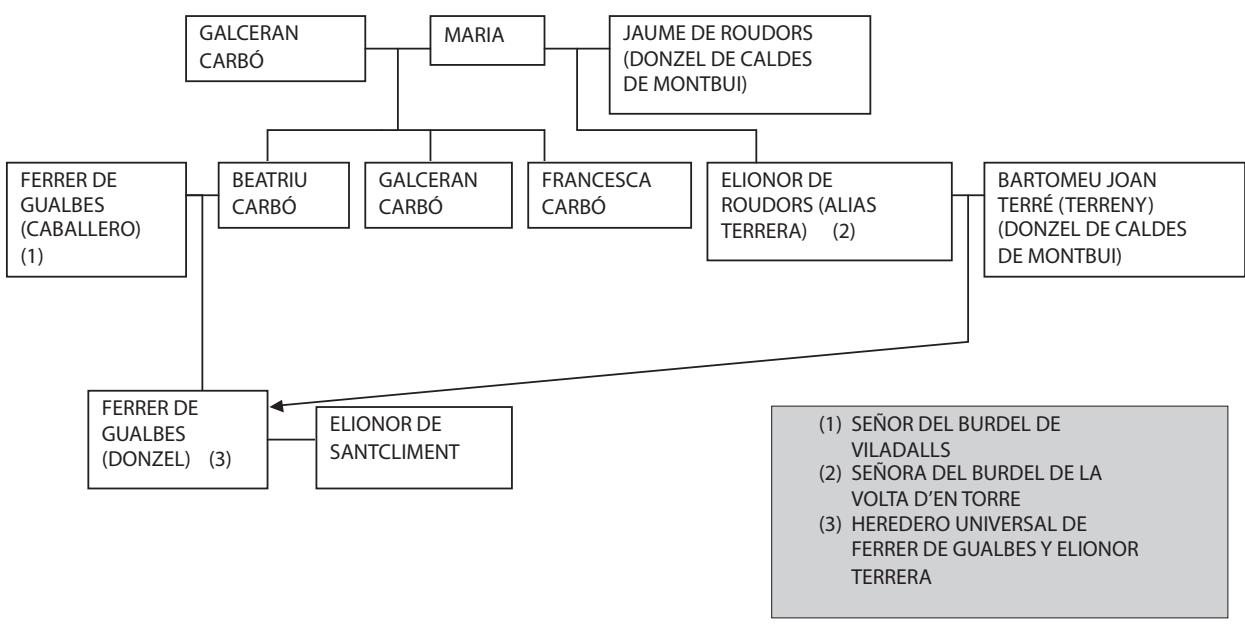


CUADROS DE LOS ALCAHUETES EXPULSADOS

\begin{tabular}{|c|c|}
\hline $\begin{array}{l}\text { NÚMERO TOTAL DE ALCAHUETES } \\
\text { EXPULSADOS (1401-1460) }\end{array}$ & 642 \\
\hline ALCAHUETES & 562 \\
\hline ALCAHUETAS & 79 \\
\hline CON OFICIO CONOCIDO & 176 \\
\hline SIN OFICIO CONOCIDO & 466 \\
\hline \multicolumn{2}{|l|}{ OFICIOS } \\
\hline Albardero & 1 \\
\hline Alguacil & 1 \\
\hline Amasador & 1 \\
\hline Ballestero & 3 \\
\hline Barbero & 33 \\
\hline Batihoja & 1 \\
\hline Bodeguero & 1 \\
\hline Bracero & 2 \\
\hline Brodador & 1 \\
\hline Calafate & 1 \\
\hline Calderero & 1 \\
\hline Campesino & 1 \\
\hline Carnicero & 4 \\
\hline Carpintero & 1 \\
\hline Cestero y sayón & 1 \\
\hline Colchero & 1 \\
\hline Contador & 1 \\
\hline Coracero & 1 \\
\hline Correero & 1 \\
\hline Cribador & 3 \\
\hline Curtidor de pieles & 4 \\
\hline Deshollador & 1 \\
\hline Escribiente & 6 \\
\hline Escribiente o escudero & 1 \\
\hline Escuder & 4 \\
\hline Espadero & 3 \\
\hline Especiero & 1 \\
\hline Estudiante & 1 \\
\hline Frenero & 1 \\
\hline
\end{tabular}




\begin{tabular}{|l|c|}
\hline Guardián & 1 \\
\hline Herrero & 8 \\
\hline Hostelero/a & 4 \\
\hline Hurgador & 1 \\
\hline Iluminador & 1 \\
\hline Jugador & 1 \\
\hline Juglar & 1 \\
\hline Ladrillero & 1 \\
\hline Maestro de casas & 3 \\
\hline Maestro de esgrima & 1 \\
\hline Marinero & 4 \\
\hline Panadero & 1 \\
\hline Pelaire & 10 \\
\hline Peletero & 6 \\
\hline Pergaminero & 1 \\
\hline Pescadera & 1 \\
\hline Pescador & 1 \\
\hline Picapedrero & 1 \\
\hline Pintor & 2 \\
\hline Platero & 2 \\
\hline Portero & 2 \\
\hline Preboste & 1 \\
\hline Revendedora & 3 \\
\hline Ropavejero & 1 \\
\hline Sastre & 13 \\
\hline Sastre o jubonero & 2 \\
\hline Sayón & 2 \\
\hline Tejedor de trapos de lino & 1 \\
\hline Tejedor & 2 \\
\hline Tejedor de seda & 1 \\
\hline Tintorero & 3 \\
\hline Tonelero & 1 \\
\hline Trajinero & 9 \\
\hline Zapatero & 176 \\
\hline Zapatero y hostelero & \\
\hline TOTAL & 1 \\
\hline & \\
\hline
\end{tabular}

